Moreno, C. y Moreno M.I. (2017). Entre la teología del reino y la teología de la prosperidad: aproximación al discurso político-religioso de las iglesias pentecostales en Caldas. Revista de Sociología y Antropología: VIRAJES, 19 (1), 209-227. DOI: 10.17151/rasv.2017.19.1.11

\title{
ENTRE LA TEOLOGÍA DEL REINO $Y$ LA TEOLOGÍA DE LA PROSPERIDAD: APROXIMACIÓN AL DISCURSO POLÍTICO-RELIGIOSO DE LAS IGLESIAS PENTECOSTALES EN CALDAS*
}

\author{
CESAR MORENO BAPTISTA** \\ MANUEL IGNACIO MORENO OSPINA***
}

Recibido: 10 de Diciembre de 2016 Aprobado: 15 de Febrero de 2017

Artículo de Investigación

\footnotetext{
* Este artículo hace parte de los resultados del macro-proyecto sobre "Identidad y desarrollo en La Dorada-Caldas" adelantado por profesores-investigadores asociados a la Maestría en Ciencias Sociales de la Universidad de Caldas; el cual ha sido apoyado por la Vicerrectoría de Investigaciones y Posgrados de la misma universidad.

** Doctor en Antropología. Profesor de la Universidad de Caldas. cesar.moreno_b@ucaldas.edu.co.

(1) ORCID: 0000-0002-6283-7952

*** Sociólogo. Magíster en Culturas y Droga. Master in Sciences Humaines Education. Docente Universidad de Caldas. manuel.moreno@ucaldas.edu.co. @ ORCID: 0000-0002-1068-0957
} 


\title{
Resumen
}

En este artículo se analiza la relación entre el discurso de las creencias religiosas de algunas iglesias pentecostales y neo-pentecostales, y su participación en la política local en el departamento de Caldas. Para ello se entrevistaron pastores de diferentes iglesias evangélicas sobre la experiencia de participación en la campaña política con motivo de las elecciones de gobernadores, alcaldes y concejos municipales a finales del año 2015. Los datos recogidos en los discursos permiten aseverar la correlación teleológica que los pastores establecen entre el campo religioso y el campo político; lo que garantiza una relación simbiótica entre el discurso y la práctica organizativa de las comunidades religiosas en función de los dos campos. Se concluye que la emergencia de las nuevas comunidades religiosas que se extienden a nivel nacional y regional, se están constituyendo en fuerzas visibles que pueden logran a futuro una incidencia importante en la política local.

Palabras clave: participación en política, creencias religiosas, pentecostalismos, neo-pentecostalismo.

\section{BETWEEN THE THEOLOGY OF THE KINGDOM AND THE THEOLOGY OF PROSPERITY: AN APPROACH TO THE POLITICAL-RELIGIOUS SPEECH OF THE PENTECOSTAL CHURCHES IN CALDAS}

\begin{abstract}
This article analyzes the relationship between the discourse of the religious beliefs of some Pentecostal and neo-Pentecostal churches and their participation in local politics in the department of Caldas. To that end, pastors from different evangelical churches were interviewed about the experience of participating in the political campaign for the elections of governors, mayors and municipal councils at the end of the year 2015. The data collected through the speeches allow affirming the teleological correlation that the pastors establish between the religious field and the political field which guarantees a symbiotic relationship between the discourse and the organizational practice of religious communities depending upon the two fields. It is concluded that the emergence of new religious communities that extend at the national and regional level are becoming visible forces that can achieve a major impact on local politics in the future.
\end{abstract}

Key words: participation in politics, religious beliefs, Pentecostalism, neoPentecostalism. 


\section{Introducción}

L a emergencia de nuevas comunidades religiosas en Colombia y América Latina, particularmente el crecimiento de comunidades denominadas evangélicas ${ }^{1}$, pentecostales ${ }^{2}$ o neopentecostales, ha cobrado interés en el análisis investigativo de las ciencias sociales en las últimas décadas. En los trabajos realizados por la línea de investigaciones sobre Diversidad y Cambio Religioso desde el año 2008 en el departamento de Caldas ${ }^{3}$, se resalta el gran número de nuevas iglesias cristianas no católicas en todos los municipios del departamento (Moreno \& Moreno, 2009; Moreno, 2012). Según estas investigaciones se calcula que en la ciudad de Manizales habría más de 100 congregaciones; mientras que para el resto de Caldas ${ }^{4}$ se estima un promedio de 200 congregaciones (o templos), agrupadas en alrededor de 36 denominaciones.

En la misma línea de investigación en 2013 (Castellanos et al.), realizan una investigación de tipo estadístico sobre el partido Movimiento Independiente de Renovación Absoluta (MIRA) en el cual se resalta la idea que su fuerza electoral se soporta en la Iglesia de Dios Ministerial de Jesucristo Internacional (IMJI).

Además del crecimiento exponencial de los nuevos movimientos, es de interés en el análisis social la participación de estas nuevas organizaciones en la actividad política local y nacional. Las nuevas fuerzas políticas han venido luchando por ampliar los espacios de participación en el poder desde hace al menos cincuenta años.

La anterior iniciativa se hace explícita en la Asamblea Nacional Constituyente de 1991, en la que las nuevas iglesias participan con dos representantes y se constituyen en pieza clave para la redacción del artículo 19, mediante el cual se garantiza la libertad de cultos en Colombia. Debido a la gran diversidad y complejidad de estas nuevas comunidades religiosas en sus formas organizativas y adaptaciones culturales, se han vuelto objeto de interés para el análisis de disciplinas como la antropología, la sociología y la historia. Diferentes publicaciones, entre las que se cuentan:

\footnotetext{
${ }^{1}$ Utilizado en este caso de manera genérica para referir a las iglesias de origen protestante norteamericano. ${ }^{2}$ El pentecostalismo, deriva del Pentecostés, término que en la tradición cristiana se refiere al descenso del Espíritu Santo sobre los discípulos de Jesús, que se conmemora en el quinto domingo después de la Pascua. El término Pentecostal designa a aquellos movimientos que enfatizan en los dones del Espíritu Santo, que se suponen asociados a la expresión de sentimientos religiosos mediante acciones de entusiasmo desinhibido: "...fueron todos llenados del Espíritu Santo, y comenzaron a hablar en diversas lenguas. Las palabras que el Espíritu Santo ponía en sus lenguas..." (Hechos, Cáp. 2, ver-4).

${ }^{3}$ La línea de investigación sobre Diversidad y Cambio Religioso está adscrita al Grupo de Investigaciones Comunicación Cultura y Sociedad de la Universidad de Caldas.

${ }^{4}$ El departamento de Caldas en su división político-administrativa cuenta con 27 municipios, incluida Manizales.
} 
Globalizacion y diversidad religiosa en Colombia ${ }^{5}$, El pentecostalismo en Colombia ${ }^{6}$, además de multiplicidad de artículos y tesis de grado y posgrado que le apuntan a indagar sobre el nuevo hecho religioso en Colombia dan cuenta de ello.

El objetivo de este artículo es analizar las argumentaciones del discurso que dan forma y validez al desplazamiento de la actividad religiosa a la acción política en las iglesias evangélicas en Caldas. En otras palabras, se trata de examinar comparativamente los principios teológicos de las corrientes religiosas pentecostales y neo-pentecostales, con el fin de comprender algunos rasgos doctrinales sobre los que estos movimientos justifican su acción política. Con este objetivo el artículo se ha estructurado en cuatro partes: la primera que busca hacer explícita la diferencia entre pentecostales y neo-pentecostales en relación con los principios dela Teología del Reino y la Teología de la Prosperidad. El segundo apartado muestra de manera general una contextualización de la emergencia de partidos de origen evangélico en las últimas décadas en Colombia. En la tercera parte, se presentan los resultados de las elecciones electorales de 2011 y 2015 en Caldas y se resaltan las principales fuerzas político-religiosas que han obtenido curules en los concejos municipales y la asamblea departamental. Finalmente, se hace un esbozo de algunos discursos de los pastores sobre los principios bíblicos que soportarían las lógicas explicativas del tránsito del campo religioso al campo político de las iglesias.

Los datos empíricos se basaron en entrevistas a diferentes líderes de iglesias evangélicas y municipios de Caldas. Igualmente se tuvieron en cuenta los datos estadísticos publicados por el DANE.

\section{Evangélicos, pentecostales y neo-pentecostales}

A finales del siglo pasado desde la década de los sesenta, se comienza a observar en las grandes ciudades colombianas la presencia de nuevas iglesias cristianas. En ese momento el desarrollo urbano y la violencia de mitad de siglo XX hicieron que se presentara una fuerte migración del campo a la ciudad ${ }^{7}$. La afluencia creciente de campesinos recién llegados a la ciudad que buscaban refugio espiritual en el mundo urbano, hizo muy

\footnotetext{
${ }^{5}$ Compilado por Ana María Bidegain y Juan Diego Demera, 2005.

${ }^{6}$ Compilado por Clemencia Tejeiros, 2010.

${ }^{7}$ Entre 1951 y 1964 Colombia pasó de tener 4.468.434 habitantes en el área urbana a 9.093.094; y de tener en el área rural una población de 7.099.735 habitantes a 8.391.423, pasando de ser un país mayoritariamente rural a mayoritariamente urbano.

Además del desarrollo industrial de las ciudades que atrajo población del campo, el fenómeno de la 'violencia' fue determinante para la migración del campo a la ciudad.
} 
pronto que los nuevos centros de culto evangélico fueran más visibles. Son estos migrantes que al entrar en un proceso de adaptación a las exigencias del mundo urbano reciben las ofertas espirituales de grupos de pentecostales en formación. Como señala Jeiman López (2010), citando a Willems, el pentecostalismo se instala en este nuevo "cambio cultural", pues es en este nuevo contexto social, en un proceso de adaptación de búsqueda de nuevos sentidos, que:

el pentecostalismo logra otorgar una nueva identidad que ofrece cierta seguridad emocional y hasta material, al mismo tiempo que reproduce cierta religiosidad popular caracterizada por la creencia en milagros, el reconocimiento del carisma en el líder religioso y la aceptación de experiencias místicas. (p. 99)

Con relación a los orígenes del movimiento pentecostal en el mundo, comúnmente se hace referencia al "despertar religioso de la calle Azusa" en la ciudad de Los Ángeles (California) en 1906. Según Petersen (1998), el movimiento se desarrolla como una forma de protesta frente al aburguesamiento de la iglesia metodista en EE.UU.

Para diferentes autores el pentecostalismo es una manifestación de la religiosidad popular en el caso latinoamericano, derivado del catolicismo, con el que comparte formas tradicionales, como imaginarios asociados a la creencia en el milagro, los demonios y las intervenciones espirituales (Beltrán, 2010).

En esta misma perspectiva, López (2010), citando a Lalive d'Epinay, señala que:

El pentecostalismo, asociado a las clases populares, ofrece un refugio (vía de escape), -frente a las lógicas excluyentes del mundo modernoque le permite vivir la nueva realidad social... su mensaje apocalíptico exige un abandono del mundo y una experiencia del Reino de Dios. Dicho abandono que implicaría un distanciamiento de las realidades sociales (miseria y pobreza) y políticas (corrupción). (p. 99).

En la perspectiva de autores como Jean Pierre Bastian o Mauricio Beltrán, el pentecostalismo representa no soloun escape, sino un movimiento de adaptación a las nuevas lógicas de mercado atendiendo a expectativas de clases medias que se identifican con el estilo de vida norteamericano. Además, es un movimiento que "incentiva la prosperidad económica entre sus fieles y predica un sistema social funcional al sistema de vida capitalista y las lógicas del mercado globalizado" (Beltrán, 2010, p. 76). Es decir, que siguiendo las "lógicas de mercado religioso" según Bastian (1997), el 
pentecostalismo no solamente es una opción religiosa frente al catolicismo y protestantismo tradicional, sino que se presenta como nuevas propuestas de organización social que influyen en las estructuras políticas y sociales del país (López, 2010).

En este mismo sentido, a diferencia de la pasividad política o huelga social de los pentecostales, las nuevas grandes congregaciones de megaiglesias neo-pentecostales tendrían la iniciativa de una participación política activa e incentivan a los fieles al proselitismo, aun reproduciendo las formas de hacer política de los partidos tradicionales (Beltrán, 2010).

Para otros autores como Jesús García, el desarrollo de diversas formas de los protestantismos norteamericanos en América Latina, aunque tuvo lugar por hondas sucesivas desde finales del siglo XIX, es en el marco de la celebración del primer congreso de Acción cristiana en 1916 en la zona del Canal de Panamá (luego de terminada su construcción), que se marca el inicio de una estrategia global de las instituciones religiosas norteamericanas con relación a América Latina y en esta misma perspectiva con la iglesia católica. La "necesidad de instaurar el verdadero cristianismo" (García, 2004).

En términos teológicos, García señala que la diferencia entre pentecostales y neo-pentecostales consiste en que mientras los primeros consideran que es necesario aislar el mundo gobernado por Satán, a la espera, de la segunda venida de Cristo para la instauración definitiva del Reino de Dios. Para los neo-pentecostales, el Reino de Dios ya ha llegado y el cristiano debe trabajar en todo aquello que sea necesario para acoger al Salvador. Es necesario entonces, transformar la sociedad incluyendo leyes transformadoras, que sean el reflejo de la doctrina bíblica. Y uno de los medios para lograrlo es ocupar espacios de poder. La participación política y el ejercicio del poder, son de esta manera justificados, ante los ojos de la mayoría de los fieles (García, 2004).

En esta misma perspectiva (García \& Michel, 2014a), la producción religiosa evangélica, se comprende dentro de una lógica de mercado global, cuyo objetivo tiende a la fabricación de individuos funcionales a dicho sistema. La religión estaría jugando un papel importante en la recomposición de ideologías en un contexto específico de la historia, al fabricar individuos funcionales al sistema de mercado imperante; así, "más que un individuo autónomo, la individualidad contemporánea tiene por finalidad producir individuos que adhieran a formas comunitarias, renovadas en correlación con las exigencias del mercado mundial" (p. 47). De otra forma señalan:

Con los neo-pentecostales, Dios ha llegado a confiar la salvación al mercado, erigiéndolo en árbitro supremo. Es ahí donde está en juego 
la relación con la teología de la prosperidad: que los bienes materiales del creyente constituyan una prueba de la benevolencia de Dios para con ellos y una validación de la lealtad que el creyente manifiesta para con dicho Dios. (p. 56)

De lo anterior se concluye, que el neo-pentecostalismo constituye una forma globalizada y globalizadora, objeto privilegiado para la antropología política de la mundialización en América Latina; es decir, las formas de fabricación de individuos por las nuevas instituciones evangélicas de un lado; y de otro lado, el planteamiento de una nueva relación entre lo político y lo religioso extremadamente fluido. El nuevo converso se presenta como siendo un actor que fluye entre lo religioso, lo económico y lo político. En esta lógica, la conversión constituye una promesa de "renacimiento espiritual", incluyendo la dimensión social y económica el mensaje pentecostal anuncia una vida mejor. "El neo-pentecostalismo se inserta en esta promesa, a la que dará forma por medio de la Teología del Reino y de la Teología de la Prosperidad" (García \& Michel, 2014a, p. 63). En esta misma perspectiva teológica, mientras que:

(...) el pentecostalismo postula retirarse del mundo, lo que lo lleva a no interesarse por las realidades sociales exteriores, mostrándose reticente en relación con el compromiso político; el neopentecostalismo, postula un proyecto en el que enuncia claramente la necesidad de transformar el mundo: es necesario que las Constituciones y las leyes sean el reflejo fiel de las prescripciones bíblicas. (García \& Michel citando a Hoge, Johnson, \& Luidens, 2014a, p. 63)

\section{Contexto general de la participación política de las iglesias evangélicas en Colombia}

La presencia de nuevos actores religiosos (particularmente cristianos no católicos) a escala local regional y nacional desde los años sesenta, ha trasformado no solo el paisaje religioso, sino que está transformando las formas de vinculación de los individuos, las familias y las comunidades. Las nuevas formas de religiosidad modifican las formas del paisaje comunitario en torno a los templos y prácticas católicas, 'destradicionalizando' y 'reterritorializando' el lugar de lo sagrado (Moreno B., 2012).

Este fenómeno creciente del evangelismo en Colombia en los años ochenta, se constituyó en potencial electoral significativo, que como se señaló más arriba, les permitió a los evangélicos elegir dos representantes a la Asamblea Nacional Constituyente de 1991, la cual ampliaría el marco 
legal sobre la pluralidad, la tolerancia religiosa, igualmente estimularía la expansión de tendencias diferentes al catolicismo (Tejeiros, 2010), y facilitaría la visibilidad de las nuevas congregaciones religiosas que desde décadas atrás venían conformándose especialmente en los centros urbanos. Actualmente, más de 5000 iglesias cristianas diferentes del catolicismo cuentan con personería jurídica en Colombia (Forero : 2013).

El proceso de participación en la Asamblea Nacional Constituyente, sería un espacio político propicio para que los neo-pentecostales tomaran la iniciativa frente al pentecostalismo tradicional que otorgaba "una connotación negativa a la política electoral, considerando la política corrupta y pecaminosa"; concepción que paulatinamente" se ha transformado para hacer de la participación electoral un mecanismo por medio del cual el movimiento pentecostal logre ampliar su influencia en la sociedad" (Cuervo, 2010). En la actualidad ambas posturas coexisten.

En la década de los ochenta el Consejo Evangélico de Colombia (CEDECOL), en el que se suman un número importante de las denominaciones derivadas del protestantismo, canalizó la discusión sobre la responsabilidad social de la participación de los evangélicos en la Constituyente a través del Movimiento Político Unión Cristiana (UC) (Ibíd.). Paralelamente, la iglesia Misión Carismática Internacional (MCI), fundada por los esposos César Castellanos y Claudia Rodríguez, tomarían la iniciativa de crear en 1989 el Partido Nacional Cristiano (PNC), quienes en concordancia con el interés expansionista del movimiento neo-pentecostal, impulsa una transformación social. (Ibíd., p. 231)

Posterior a la constitución de 1991 surgieron nuevos partidos dentro de las iglesias evangélicas como la Iglesia Pentecostal Unida de Colombia en el año1993 que crea el movimiento Alianza Moral por Colombia (AMOR); la hoy senadora y ex-fiscal de la Nación Vivian Morales fundó en 1994 el Movimiento Político Frente de Esperanza (FE) (Ibíd.). Otros movimientos políticos que han emergido de las nuevas comunidades religiosas se han mantenido como independientes a fin de captar el voto de opinión como fue el caso del Compromiso Cívico Cristiano con la Comunidad (C4) de Jimmy Chamorro, que entre 1992 y 2006 logró mantenerse como senador de la república durante tres periodos. Por su parte, el Movimiento Independiente para la Renovación Absoluta (MIRA), derivado de la Iglesia de Dios Ministerial de Jesucristo Internacional (IDMJI) apareció en sus primeros comicios electorales en 2000 y se ha mantenido activo hasta la fecha. 
Con la reforma política de 2003 con la cual se modificó el régimen de los partidos políticos y el sistema electoral, favoreciendo los macro-partidos, muchos de los partidos que habían emergido de los nuevos movimientos religiosos perdieron su personería jurídica. Así es que, empiezan a surgir las alianzas con los partidos políticos mayoritarios; por ejemplo, el PNC de Claudia y César Castellanos en el 2005 se integró al Partido Cambio Radical (Ibíd.). Jimmy Chamorro volvió a la arena electoral en lista del partido de la U para la campaña 2014-2018 en la que logró 61.005 votos, según la Registraduría y obtuvo una curul en el Senado.

El partido MIRA que hasta el momento había tenido una base pequeña, con la reforma política, se propone abrir sedes en todo el territorio nacional hasta hacerse presente prácticamente en todos los departamentos del país. En el 2010 el MIRA contaba nacionalmente con: 22 concejales, un alcalde, dos senadores, un representante a la cámara, tres diputados y 129 ediles 8 .

\section{Crecimiento de los evangélicos en el departamento de Caldas}

El emplazamiento local, nacional e internacional realizado por estos movimientos religiosos les ha permitido desarrollar una red de templos ${ }^{9}$ sobre los cuales se ha ido configurando la base social de la actividad política. La presencia de las iglesias evangélicas en Caldas inicia a mediados del siglo XX. A finales de los años cincuenta hace presencia en la región del Magdalena Centro ${ }^{10}$ la Alianza Misionera de Colombia, y paralelamente en Manizales la Iglesia Pentecostal Unida de Colombia (IPUC) empezó a funcionar a principios de la década de los 60.

Desde los años cincuenta que se inicia la aparición de iglesias evangélicas en el departamento, su crecimiento ha sido progresivo hasta la actualidad, particularmente en la capital, Manizales. Ya en la década del setenta en Manizales se contaban alrededor de 15 iglesias (no católicas) y al final de la década del ochenta se contabilizan 21 iglesias, y en la década del noventa 38 iglesias. En la primera década del siglo XXI se contabilizaron

\footnotetext{
${ }^{8}$ En: “rendición de cuentas 2009-2010" del Movimiento Político MIRA. Bogotá 2010.

${ }^{9}$ La Misión Carismática Internacional cuenta con 160 sedes en el mundo y 25000 miembros en Bogotá, transmiten su mensaje doctrinal a través de la cadena TV ENLACE que llega a 140 países, un canal online de G12 Tv, en: http://mci12.com/\#nuestraiglesia/. La Iglesia de Dios Ministerial de Jesucristo Internacional hace presencia en cerca de 50 países y en los 32 departamentos de Colombia, que suman alrededor de 500 templos En: http://idmji.org/direcciones/

${ }^{10}$ Territorio en el departamento de Oriente de Caldas. Su principal ciudad es La Dorada. Además, lo conforman los municipios de Norcasia, Samaná, Marquetalia, Manzanares, Pensilvania y Victoria.
} 
60 iglesias, y en la actualidad se estima un aproximado de más de 100 iglesias o congregaciones en Manizales (Moreno \& Moreno, 2009). En el resto de municipios del departamento, durante las décadas de los sesenta, setenta y ochenta se evidencia un crecimiento lento, pero en los siguientes 20 años (entre 1990 y 2010) se dispara la creación de nuevos templos con un estimativo de 200 congregaciones, excluyendo Manizales del resto de Caldas (incluidos los municipios de Villamaría y La Dorada) (Moreno, 2012).

Es importante señalar que si bien el crecimiento de templos es acelerado en las últimas décadas en Caldas, el crecimiento de la membrecía no sucede al mismo ritmo que en otras ciudades del país. A partir de algunos datos proporcionados por la encuesta realizada por Beltrán en el 2011 en Medellín, Bogotá, Barranquilla, Cali y Bucaramanga, se puede concluir que: Medellín tendría el 9,5\% de evangélicos del total de su población, Bogotá 14,5 \%, Barranquilla 23,4\%, Cali 21,5\%, Bucaramanga 24,3\%. Ahora bien, según los datos que hemos calculado para Manizales (Moreno \& Moreno, 2009), es de entre 3\%. Es decir, que comparativamente podemos obtener la siguiente tabla.

Tabla 1. Comparativo porcentual del crecimiento de las iglesias evangélicas en principales ciudades del país en relación con Manizales.

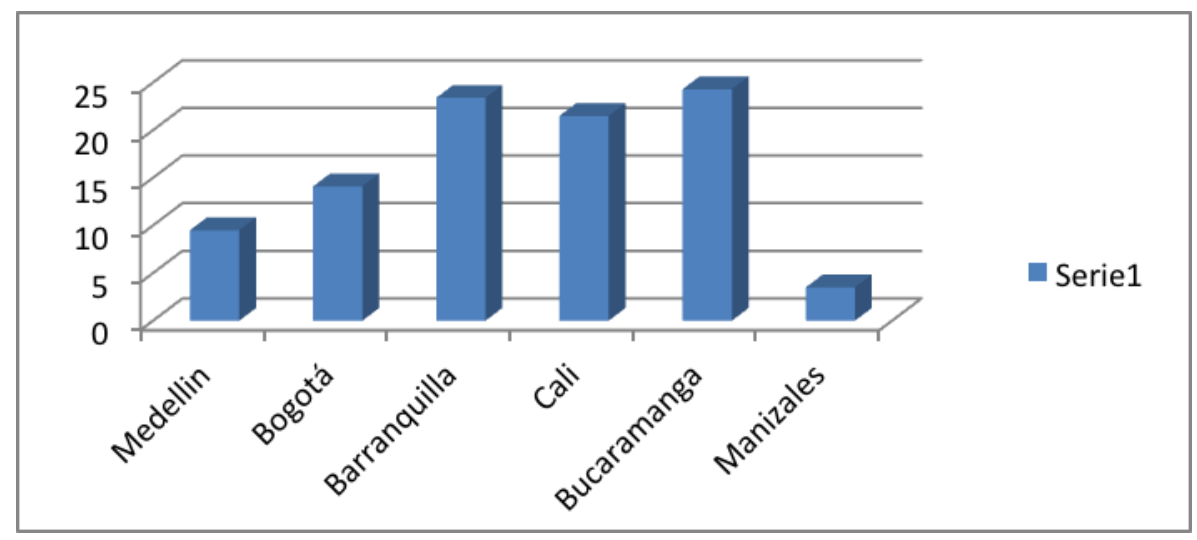

Fuente: Elaboración propia. 
Como se desprende de la gráfica, Medellín, Barranquilla y Bucaramanga tienen un porcentaje superior al $20 \%$ de su población, Las sigue Bogotá con una membresía del 15\%, mientras que Medellín con el $9,5 \%$ es la que de las tres más grandes ciudades del país cuenta con un $9,5 \%$. Manizales cuenta con el porcentaje más bajo con 3\%, lo que podría explicarse por su fuerte arraigo a la tradición católica.

Situados en ese 3\% de nuevos creyentes en Caldas podríamos decir que el desplazamiento del campo religioso al campo político encontramos dos ejemplos significativos representados en el partido MIRA derivado de la IDMJI. El segundo ejemplo lo encontramos en la Asociación de Ministros Cristianos de Caldas.

En el caso del MIRA, como ya se hace presencia en gran parte del trabajo de expansión nacional de la red del movimiento en los primeros 10 años de creación. Es decir, que para el 2010 el MIRA al igual que la IDMJI se ha establecido prácticamente en todos los municipios de Caldas. Donde había un templo de IDMJI se encontraba una sede del MIRA.

Por otro lado, ASMICC, que se constituye en una red de iglesias interdenominacionales desde los años noventa que tiene un interés de cooperación doctrinal, pero con aspiraciones políticas.

Las dos organizaciones operan con diferentes lógicas: la primera ha sido una organización que ha mantenido su autonomía como partido político y se ha desarrollado con base a los elementos característicos de la iglesia neo-pentecostal.

La segunda se encuentra en proceso de conformación, cuya mayor parte de las iglesias que tienen se basan en una teología de corte pentecostal.

\section{El Movimiento Independiente de Renovación Absoluta (MIRA)}

En el terreno político se destaca los resultados del MIRA de la IDMJI, que en el transcurso de su creación del 2000 al 2015 en el departamento de Caldas han logrado 11 curules: 10 en el concejo municipal. Como se observa (en la tabla 2), el MIRA, en las elecciones de concejo municipal, alcanzó en las elecciones de 2011 una curul en tres municipios (Chinchiná, Manizales y Villamaría), en total una votación de 11.165 votos en los tres municipios.

En las elecciones de 2015 el MIRA alcanzó una curul (cuatro más que en las anteriores elecciones) en siete municipios de Caldas: Aguadas, Anserma, Chinchiná, La Dorada, Manizales, Risaralda, Villamaría (sumada una votación de 13.202 votos). Comparativamente con las elecciones del 2011 se mantuvo la curul de Chinchiná, Manizales, Villamaría, y se obtuvieron cuatro nuevas curules en Aguadas, Anserma, La Dorada y Risaralda. 
Tabla 2. Curules obtenidas por el partido MIRA en elecciones regionales para concejo municipal y asamblea departamental en Caldas, 2011 y 2015.

\begin{tabular}{lcccccc}
\hline \multicolumn{7}{c}{ Concejo Municipal } \\
\hline \multicolumn{1}{c}{ Elecciones 2011} & \multicolumn{3}{c}{ Elecciones 2015 } & \\
\hline Agunicipio & curules & votos & $\begin{array}{c}\text { \% } \\
\text { votación }\end{array}$ & curules & votos & \% \\
Anserma & & & 1 & 609 & 6,11 \\
Chinchiná & 1 & 1519 & 7,72 & 1 & 1005 & 6,61 \\
La Dorada & & & & 1 & 1415 & 5,24 \\
Manizales & 1 & 8449 & 6,39 & 1 & 7177 & 4,46 \\
Risaralda & & & & 1 & 378 & 6,87 \\
Villamaría & 1 & 1197 & 6,22 & 1 & 1448 & 6,68 \\
\hline Total & 3 & 11165 & & 7 & 13202 & \\
\hline
\end{tabular}

Fuente: Registradora Nacional del Estado 2011 y 2015 (resultados electorales).

En cuanto a las elecciones para asamblea departamental, el MIRA ha logrado obtener una curul en las elecciones de 2011 con 18.579 votos, pero en las elecciones de 2015 perdió la curul con 16.950 votos.

\begin{tabular}{cccccc}
\hline \multicolumn{5}{c}{ Asamblea Departamental } \\
\hline \multirow{2}{*}{ Elecciones 2011 } & \multicolumn{4}{c}{ Elecciones 2015 } \\
\hline \multirow{2}{*}{ curul } & votos & $\%$ & curul & votos & $\%$ \\
& 18.579 & 5.56 & 0 & 16.950 & 4.51 \\
\hline
\end{tabular}

\section{La Asociación de Ministros Cristianos de Caldas (ASMICC)}

Otro de los proyectos políticos de las iglesias evangélicas en Caldas, gira en torno a la Asociación de Ministros Cristianos de Caldas (ASMICC), que se formaliza a principios de los años noventa. En la actualidad, ASMICC reúne aproximadamente 60 iglesias donde confluyen diferentes denominaciones. Uno de los elementos característicos de las iglesias de esta asociación es que profesan la "sana doctrina", es decir, que se consideran "cristianos trinitarios". La primera condición para hacer parte 
de la asociación es declararse teológicamente trinitarios, es decir, que alaban y creen en la trinidad católica (Padre, el Hijo y el Espíritu Santo ${ }^{11}$ ). Aunque la asociación está abierta a la participación de todas las iglesias del departamento, se ha desarrollado una mayor integración entre las iglesias de Manizales.

Dentro de la asociación diferentes iglesias adelantan acciones de cooperación, como la circulación de pastores por diferentes congregaciones realizando trabajo de predicación, y también en la realización de eventos masivos de alabanza en estadios y escenarios públicos.

ASMICC había tenido un interés de participación política desde sus inicios sin ningún éxito. Fue hasta las elecciones del 2015 que lograron unificar una candidatura en torno a una lideresa de la Misión Carismática Internacional y elegirla como concejal de Manizales con 1904 votos. La elección de esta candidata se hizo en coalición con el Partido de la U ${ }^{12}$. De acuerdo con los testimonios de diferentes pastores, se habían hecho varios intentos de elegir un concejal en coalición con otros partidos, pero la división interna no había permitido tener éxito.

Los nuevos actores religiosos transitan a la escena política jalonados por argumentos que se fundamentan en su filiación religiosa y la defensa de determinados valores e intereses que se interpretan en función social. Estos principios doctrinales se constituyen en determinado momento en dispositivo de articulación inter-denominacional entre iglesias o de coalición con partidos políticos ${ }^{13}$. Por ejemplo, para uno de los líderes de la MCI en La Dorada, la iglesia debe ser un generador de cambios, una fuerza que logre su proyecto de vida fuera de las cuatro paredes de la iglesia y se proyecte a la comunidad:

Nosotros no nos consideramos como una iglesia de seguidores sino de sucesores. Es decir que la Misión Carismática también tiene una visión de lo social muy amplia, incursionamos en la política del país. Actualmente tenemos tres congresistas en la bancada Centro Democrático defendiendo el orden natural de Dios. (Pastor MCI).

\footnotetext{
${ }^{11}$ Por ejemplo, en ASMIC consideran que Ias ideas religiosas de la IDMJI no son aceptadas, particularmente en la creencia del dogma de la profecía.

${ }^{12}$ Las alianzas con otros partidos como el caso de la MCI -cuyo principal aliado ha sido el Centro Democrático- se establecen a través del movimiento CRC que son las iniciales de la líder política Claudia Rodríguez de Castellanos, considerada "el motor político de la iglesia", es exsenadora de la República, exconcejal de Bogotá y exembajadora en Brasil en el gobierno de Álvaro Uribe Vélez.

${ }^{13}$ Como se ha señalado, el principal argumento que los articula es la defensa de la familia, en oposición a la legalización del aborto, el matrimonio igualitario, la adopción igualitaria y la legalización de las drogas.
} 
Aquí es claro que para las iglesias neo-pentecostales como la MCI, ésta debe ser un generador de cambios sociales mediante acción política. Para las iglesias pentecostales (como en su mayoría componen ASMIC), aunque se alejan de una teología de la prosperidad han comenzado -en sus términos- un 'despertar' y 'desengañarse' de su creencia de la inmoralidad por la acción política ${ }^{14}$.

\section{La creencia religiosa como resorte del campo político}

A diferencia de las primeras versiones pentecostales, las nuevas están orientadas hacia "este mundo", no enfatizan la salvación para "la otra vida", ni el advenimiento inminente de Jesucristo. Además, no condenan la política, sino por el contrario justifican la participación de los creyentes en ella, como parte de su misión de establecer el reino de Dios en la tierra. En este sentido: las nuevas versiones pentecostales afirman que tanto la "prosperidad económica" como el "poder político" son aspiraciones legítimas de los "los hijos de Dios". Esta nueva actitud se puede expresar en el tránsito de "la huelga social" a la "teología de la prosperidad" (Beltrán, 2006, p. 34).

Ya Bourdieu (1971) afirma como en cualquiera de los campos en este caso "religioso", se construye alrededor del interés la expectativa de un mensaje sistemático capaz de dar un sentido unitario a la vida, en torno a la conducta cotidiana. Las creencias de los actores se configuran en un habitus religioso particular, es decir una disposición durable, generalizadora y transportable de la acción.

Las creencias religiosas tienen un rol importante en la creación y sustento de esquemas de percepción, es decir en la relación entre estructuras de poder y estructuras mentales. Resulta inevitable el nexo entre el campo religioso y el campo político. Pues explica Bourdieu (1971), función ideológica entendida como "la práctica y política de hacer absoluto lo relativo y de la legitimación de lo arbitrario" (p. 310), contribuye a la “imposición (disimulada) de principios de estructuración de percepción y de pensamiento del mundo y, en particular, del mundo social" (p. 300). Así pues, la dialéctica entre la teología del reino y la teología de la prosperidad implica la relación entre el campo religioso y el campo político.

\footnotetext{
${ }^{14}$ La posición que han asumido comúnmente las iglesias pentecostales se expresa en palabras de un pastor de la Misión Panamericana: "en el caso particular de nosotros como Denominación Panamericana, le enseñamos a la gente de alguna manera como descubrir un buen perfil, mas no imponemos ideologías, ni nombres, ni tenemos brazos políticos, ni acuerdos políticos. Algunas denominaciones lo hacen, nosotros no".
} 
Una de las características importantes para las iglesias neopentecostales es mantener firme la creencia de la presencia del Reino de Dios en la tierra y que dicha presencia significa bienestar para la membrecía de la iglesia tanto en el mundo espiritual como en el material, como lo señala el pastor Hernando Zapata:

En Suramérica por el año 2010 se empezó a hablar del Reino de los Cielos más que del Evangelio de Salvación. Porque el Evangelio de Salvación era venga bautícese, comience a cantar en la iglesia, i que crezca la iglesia! (...) El Reino de los Cielos empezó a descubrir que Dios es tan perfecto que él puede incrustarse, o puede incursionar en lo político, en lo deportivo, en lo social, en lo económico. Por ejemplo, actualmente yo hago un trabajo de marketing de político, con algunos pastores y algunos cristianos. (Líder, Iglesia Centro de Fe y Esperanza)

\section{Con relación a la participación en política, el pastor Antonio Ordóñez de la MCI comenta:}

Para entender la relación religión política, hay que ir a la Biblia y vamos a encontrar palabras como proverbios 29-2 que dice: cuando gobierne el justo el pueblo es alegre, cuando gobierne el impío el pueblo gime (...) Una de las consignas del M-19 era la paz nace de la justicia. Justamente es un pasaje bíblico. (...) Romanos 13 nos habla de las autoridades, del gobierno. El tributo al Estado. El cristianismo es poder político capaz de hacer grandes transformaciones en una nación. Mucho tiempo se malinterpretó 'mi reino no es de este mundo', como si fuera una acción de alejarnos de las necesidades humanas. Al contrario, debemos tener el corazón con Dios bien conectado en la esfera espiritual de lo invisible, pero los pies en la tierra bien conectados a una comunidad que necesita conocer de Dios, en esencia la política es un arma evangelista de la iglesia, una cosa es politizar la iglesia, otra cosa es cristianizar la política. Necesitamos gente que gobierne, entonces la iglesia lo que tiene que promover es aquellas personas sobresalientes que tengan vocación y motivarlos a que entren en la esfera del Estado y muchos que están en el Estado que se conviertan a la fe cristiana. (Pastor, MCI)

Se puedeevidenciar en este testimonio, comola teodicea presente en las doctrinas de los neo-pentecostales, el creyente asume sus responsabilidades frente a Dios y las cumple a cabalidad, incluyendo las de militante, que hacen parte de una dimensión, entre otras, en su vida. La teodicea aporta una 'solución' al problema o la necesidad de que el líder religioso incursione en campo de lo político. Se justifica por que será allí donde se concretarán 
los bienes de salvación en la tierra. La teodicea implica una creencia en el 'otro' mundo, creencia en la retribución y esta se logrará a través del orden político como medio para la transformación ética racional del mundo.

De acuerdo con Max Weber (1967) podemos decir que el ascetismo intramundano del afiliado a las iglesias neo-pentecostales, le convence de ser una herramienta de Dios en el mundo, las recomendaciones de los líderes políticos de cómo proceder se convierten en un deber moral para el creyente, quien asume la transformación del mundo según sus ideales ascéticos, bajo unos parámetros definidos; porque si Jesús vendrá nuevamente al mundo, entonces se lo debe recibir bien, en condiciones adecuadas, la aprehensión de un comportamiento éticamente político, consecuente y adecuado con la formación de una ciudadanía activa y enmarcada en los requerimientos que la ley establece.

Ahora bien, esto tiene una conexión con lo teleológico. En función de la búsqueda de las bendiciones "prometidas por Dios", los militantes/ creyentes terminan adoptando ciertas formas de comportamiento, que por una afinidad electiva, devienen en un proceder acorde con el ejercicio partidista y ciudadano que se esperaría en cualquier partido político. Si en función de agradar a Dios y aportar lo justo para construir su reino, las personas no roban, militan de manera voluntaria, no se dejan corromper, tratan de ser transparentes y usan los instrumentos legales, lo que están haciendo es fortalecer el ejercicio ciudadano, pero bajo un principio religioso.

Tanto pentecostales como neo-pentecostales afirman tener un sueño de sociedad y una función de lo religioso, que justifica su participación o no en política. En el caso de la IMJI, se explica a través de la creencia en los 'dones', "considerado como un regalo de Dios a su Iglesia y su adquisición depende del grado de compromiso de los fieles, del tiempo de permanencia en la iglesia y de haber sido bautizado en el Espíritu Santo o bautizado en agua" (Reyes, 2010, p.191).

A su vez, las dinámicas de los miembros de la IMJI son regidas por los mensajes que se comunican a través de la 'profecía'15, en este sentido el profeta predestinado por Dios para cumplir con la misión de propagar su reino por el mundo es María Luisa Piraquive (2002., p.193), así lo afirma la pastora:

Como les había referido, el Espíritu Santo se anticipó con revelaciones acerca de la Iglesia y su participación en el gobierno (...) Inesperadamente Dios propició las cosas, movió los corazones e

\footnotetext{
${ }^{15}$ La profecía parte de la idea que Dios lo sabe todo, pasado, presente y futuro, así Dios le revela, a algunas personas, fragmentos de aquello que considera (Reyes, 2010, p. 193).
} 
incitó la creación del Movimiento Político MIRA. Por mi mente jamás pasó que nos fuéramos a ver envueltos en semejante labor, realmente no había ninguna necesidad de hacerlo, mas el Plan de Dios así lo dictaminó. Entendí que la enseñanza de Isaías 60:3 cuando afirma respecto de la Iglesia que los pueblos andarán a tu luz y los reyes al resplandor de tu nacimiento, se vivifica con MIRA (no después de la muerte o cuando Cristo venga en las nubes). (Ibíd, p. 150).

El partido procede esencialmente con el objetivo de salvar almas para Dios y dar espacio a aquellos que estén dispuestos a compartir los ideales de la Iglesia. En este caso la elegida es la portadora del mensaje a la feligresía.

Las iglesias que han adoptado la teología o evangelio de prosperidad han adaptado tecnologías modernas a los espacios de culto, han utilizado la radio y la televisión, para transmisión en vivo de las jornadas pastorales a nivel nacional e internacional. La misma teología les señala la importancia de hacer sacrificios a favor de la Iglesia mediante el diezmo como una forma de agradar al Señor. Un indicador muy importante de la prosperidad lo constituye la membrecía, lo que se asocia al número de iglesias distribuidas a lo largo y ancho del territorio y en ese mismo sentido toda la actividad política constituye un sacrificio de los miembros de la iglesia por la prosperidad y el éxito de ésta (Reyes, 2010).

\section{Conclusiones}

La emergencia del gran número de templos y denominaciones religiosas evangélicas en las últimas décadas confirma la pluralización del campo religioso a nivel nacional, regional y local. A pesar de que su crecimiento en el Caldas, no se muestra al mismo ritmo de otras regiones y ciudades, la incidencia de estas nuevas iglesias es factor de reconfiguración de nuevos sentidos de identidad comunitarios y modos de creer en la sociedad (Hervieu-Leger, 2005). Paralelamente desde el reconocimiento de la diversidad religiosa en el país con la constitución de 1991 se han formalizado nuevos partidos políticos de origen religioso, cuya base electoral y organizativa lo constituyen los fieles de las iglesias evangélicas.

$\mathrm{Si}$ bien es cierto que existe un sustrato común de dichas creencias entre las dos corrientes religiosas más importantes: pentecostales y neopentecostales, mientras los primeros piensan que es necesario distanciarse de satanás en términos de una "guerra espiritual", y esperan la segunda venida de Cristo para instaurar el Reino de Dios; para los neo-pentecostales, el Reino de Dios ya llegó y todo cristiano debe trabajar para que todo esté adecuado para recibir al Salvador. Según estos, es entonces necesario 
transformar la sociedad y las leyes para que la realidad refleje los textos bíblicos. Los diferentes principios doctrinales y su actitud frente a la sociedad han permitido diferenciar a los pentecostales y los neo-pentecostales como movimientos que tienen variedad de predisposiciones frente a la acción política.

Los neo-pentecostales por su gran interés en promover la participación cívica y política de sus fieles y sus líderes pastorales en la sociedad, la promoción del liderazgo de la mujer en las iglesias, el uso sofístico de los medios masivos y la tecnología de mercado, y la promoción de la teología de la prosperidad acompañada por una orientación de prosperidad económica, han logrado producir un mensaje atractivo particularmente en los sectores de clase media y generar nuevos seguidores así como réditos electorales.

De acuerdo con los datos electorales de las elecciones de 2011 y 1015 se puede concluir que en Caldas, los resultados más significativos los ha obtenido el partido MIRA de tendencia neo-pentecostal que ha logrado tener permanencia representativa durante ocho años (dos periodos consecutivos) en tres municipios, incluido Manizales, y ampliaron en los últimos cuatro años su representación en cuatro municipios más. Es decir, actualmente cuentan con representatividad política, aunque en minoría, en una cuarta parte de los municipios de Caldas.

De otra parte, las "iglesias trinitarias", asociadas en ASMICC dentro de la que se identifica iglesias con posturas de tendencia legalista ${ }^{16} y$ moderada ${ }^{17}$, cuyos contrastes reflejan una mayoría de denominaciones con tendencia pentecostal y una minoría neo-pentecostal, como la Misión Carismática Internacional. El hecho de que en 2015 la candidata de ASMICC en coalición con el Partido de la U, tenga su origen su iglesia de congregación en la Misión Carismática Internacional da cuenta de la capacidad de los neo-pentecostales para ir ganando espacio político en la sociedad.

\section{Referencias bibliográficas}

Bastian, J. (1997). La mutación religiosa de América Latina. México: FCE.

Beltrán, W.M. (2010). La expansión del pentecostalismo en Colombia. Una revisión del estado del arte. En: Tejeiros, C. (compiladora). El pentecostalismo en Colombia. Prácticas religiosas, liderazgo y participación política. Bogotá: Universidad Nacional de Colombia.

\footnotetext{
${ }^{16}$ Se podrían señalar como una tendencia más ortodoxa, con prescripciones rígidas.

${ }^{17}$ Con una disposición más liberal y abierta, o menos restrictiva.
} 
Beltrán, W.M. (2011). Descripción cuantitativa de la pluralización religiosa en Colombia. Universitas Humanistica, (73). No.73. Pp. 173-200.

Beltrán, W.M. (2006). Pentecostales y neo-pentecostales: lógicas del mercado y consumo cultural. Cuadernos de trabajo del GESRSC, (4). Bogotá: Universidad Nacional de Colombia.

Beltrán, W.M. (2000). Socio-génesis de la participación pentecostal en el campo político electoral colombiano. Paz-ando, (16). Pp. 1-11.

Bidegain, A.M. \& Demera, J. D. (compiladores). (2005). Globalización y diversidad religiosa en Colombia. Bogotá: Universidad Nacional de Colombia.

Bourdieu, P. (1971). Génesis y estructura del campo religioso. México: Fondo Cultura Económica.

Castellanos, J.M.; Tapasco, O.; Gallego, C.A.; Osorio, D.; Urrea, S.; Orozco, L.; Espeleta, J. et al. (2013). El movimiento independiente de Renovación Absoluta y la producción de incentivos religiosos para la acción política en Manizales (Colombia). Manizales. Revista de Antropología y Sociología, Virajes, 15 (1).

Cuervo, I. (2010). Trayectorias y agendas de mujeres pentecostales en la política. Los casos del movimiento Unión Cristiana y del Partido Nacional Cristiano. Colombia (1991-2005). En: Tejeiros, C. (compiladora). El pentecostalismo en Colombia. Prácticas religiosas, liderazgo y participación política. Bogotá: Universidad Nacional de Colombia.

Forero, Andrea. Entre 15 y 20 nuevas iglesias son registradas cada semana en Colombia. El Tiempo. (6 de octubre de 2013).

Colombia elecciones regionales 2015 (2015). Recuperado de http://elecciones.registraduria. gov.co:81/esc elec 2015/99CO/DCO09ZZZZZZZZZZZZZZZ L1.htm

Colombia elecciones regionales (2011). Recuperado dehttp://www.colombia.com/especiales/ elecciones_2011/resultados/Concejo.aspx?D=9

García-Ruiz, J. \& Michel, P. (2014b). Neo-pentecostalismo y globalización. Recuperado de: https://hal.archives-ouvertes.fr/hal-01025311/document

García, J. (2012). Sociología del crecimiento y la decadencia de las instituciones religiosas en la globalización. En: Revista de antropología y sociología: Virajes, 14 (2), 157-170.

Garcia-Ruiz, J. (2004). Le néopentecôtisme au Guatemala: entre privatisation, marché et réseaux. Critique Internationale, 22, 81-94.

Hervieu-Leger, D. (2005). La religión, hilo de memoria. Barcelona: Heder.

López, J. (2010). Interpretaciones y perspectivas de estudio del pentecostalismo en América Latina. En: Tejeiros, C. (compiladora). El pentecostalismo en Colombia. Prácticas religiosas, liderazgo y participación política. Bogotá: Universidad Nacional de Colombia.

Moreno, C. (2012). Cambios socioreligiosos y estrategias de emplazamiento de las iglesias pentecostales en Caldas. Revista de antropología y sociología: Virajes, 14 (2), 173-212.

Moreno, C. \& Moreno, M. (2009). Prospección etnográfica del cambio religioso en la ciudad de Manizales. Revista de Antropología y Sociología: Virajes, 11, 177-203.

Piraquive, M.L. (2002). Vivencias. Colombia: Iglesia de Dios Ministerial de Jesucristo Internacional.

Reyes, G.M. (2010). El don de la profecía en la Iglesia de Dios Ministerial de Jesucristo Internacional. En: El pentecostalismo en Colombia. Prácticas religiosas, liderazgo y participación política. Bogotá: Universidad Nacional de Colombia.

Tejeiros, C. (2010). Pentecostalismo en el marco del cambio social y religioso en América Latina y Colombia. En: El pentecostalismo en Colombia. Prácticas religiosas, liderazgo y participación política. Bogotá: Universidad Nacional de Colombia.

Weber, M. (1967). La ética protestante y el espíritu del capitalismo. México: Fondo de Cultura Económica. 